\title{
Constituição, Situação e Dinâmica de Arranjos Produtivos Locais: O Caso do APL de Açaí na Região do Grão-Pará (2002 a 2010)*
}

\section{Local Productive Systems, Dynamic and Growth: A Methodology Applied to the LPS of Fruits in Northeastern Pará (2002 to 2010)}

\author{
Francisco de Assis Costa** \\ Danilo Araújo Fernandes*** \\ Cleidianne Novais Sousa Crispim****
}

Resumo: Comparando resultados de três pesquisas relativas aos anos de 2002, 2007 e 2010, o artigo analisa a dinâmica de crescimento do arranjo produtivo local de frutas do nordeste paraense. Lançando mão da noção cunhada pela Escola Francesa da Regulação, de regime de crescimento, os principais resultados são que o regime de produtividade do aglomerado tem garantido rendimentos crescentes de escala, com contribuições de inovação e cooperação. Trata-se, porém, de dinâmica de crescimento com condicionalidades associadas a uma taxa média de lucro decrescente. Assim sendo o regime de demanda se conformou de modo que pressões de baixa sobre os preços dos produtos finais se combinam com elevação dos preços das matérias-primas fundamentais das empresas industriais do APL. A isso soma-se um regime institucional que favorece a crise que atinge muitas empresas do arranjo, exigindo providências que são alinhavadas nas considerações finais.

Palavras-chave: Arranjos produtivos locais. Aglomerados produtivos. Economia local. Regime de crescimento.

Abstract: Comparing results of three surveys in the years 2002, 2007 and 2010 the article analyzes the dynamics of the Local Productive System (LPS) of Fruits in Northeastern Pará. Applying the Regulation Theory's notion of growth regime the text finds out that the productivity regime of the agglomerate has been guaranteeing increasing returns to scale, with contributions of innovation and cooperation. It is, though, a growth dynamics with constraints associated to a rate average of decreasing profit, for the "demand regime" was conformed so that pressures on the prices of the final products combine with elevation of the prices of major inputs of the industrial plants of the LPS. Finally an institutional regime, which favors the crisis that reaches

\footnotetext{
* Trabalho executado no contexto da RedeSist, com apoio do Sebrae.

** PhD em Economia pela Freie Universität de Berlin (Alemanha). Professor titular do Programa de Pós-Graduação em Desenvolvimento Sustentável do Trópico Úmido da NAEA da Universidade Federal do Pará (UFPA). E-mail: francisco_de_assis_costa@yahoo.com.br

*** Doutor em Desenvolvimento Socioambiental pelo Núcleo de Altos Estudos Amazônicos da Universidade Federal do Pará (UFPA). Professor adjunto do Programa de Pós-Graduação em Desenvolvimento Sustentável do Trópico Úmido do NAEA da Faculdade de Ciências Econômicas e do Programa de Pós-graduação em Economia da UFPA. E-mail: danfernandes2@hotmail.com

**** Doutoranda do Programa de Pós-graduação em Economia da Universidade Federal do Pará (UFPA). Professora adjunta da Faculdade de Ciências Econômicas da UFPA. E-mail: cleidinsousa@ gmail.com
} 
many companies of the arrangement, is added to the picture, requiring measures that are basted in the final considerations.

Keywords: Local productive systems. Local economy. Productive clusters. Growth regime.

JEL Classification: B52; E12.

\section{Introdução}

A economia do açaí da vasta área composta pelas mesorregiões Nordeste Paraense, Região Metropolitana de Belém e Marajó, no Pará, que chamaremos daqui por diante de Região do Grão-Pará, para aludir ao fato de que se trata da região de colonização mais remota da Amazônia, vem apresentando dinâmica notável nos últimos anos. Estima-se que, entre 2000 e 2011, o valor adicionado da produção de polpa de açaí, incluindo as etapas de produção agrícola e industrial, e de comércio, saltou de $\mathrm{R} \$ 364$ milhões para $\mathrm{R} \$ 1,9$ bilhão (COSTA, 2016). Trata-se de economia com reconhecida importância estratégica para um desenvolvimento sustentável e inclusivo. No seu lado rural, está amplamente baseada em formas camponesas de manejo de recursos ecossistêmicos e sistema agroflorestais; no lado industrial, fortemente ancorada em pequenas e médias empresas e capacidades locais (COSTA, 2016; BRONDIZIO, 2010; SILVA, 2017).

A produção de polpa de açaí na Região do Grão-Pará tem-se feito, há muito, artesanalmente, por estruturas produtivas com escalas compatíveis com a força de trabalho de uma família, a que se denominam, localmente, de "batedores de açaí”. Ancoradas nas raízes culturais profundas do consumo do açaí na região, essas minúsculas empresas informais se distribuem difusamente para atender uma demanda estritamente local, por vezes alocada num raio que alcança alguns quarteirões das cidades maiores. São milhares os "batedores de açaí”, que nas sedes dos municípios da região e, sobretudo, em Belém, onde se estima serem acima de três mil, abastecem um mercado fiel e ávido.

Pesquisa por nós realizada em 2002 (COSTA; ANDRADE; SILVA, 2006) expôs um fato novo na Região do Grão-Pará: a emergência recente de uma estruturação de processamento industrial de frutas, com mais de $80 \%$ da produção voltada ao açaí, constituída por empresas formais, em geral pequenas, porém bem maiores que os "batedores de açaí" tradicionais, baseadas na produção rural local, extrativa ou agrícola, camponesa ou empresarial, orientadas principalmente aos mercados local e nacional, principalmente do Nordeste e do Sudeste do país. A exportação para o resto do mundo era já realidade, porém apenas se esboçava.

O objetivo deste artigo é acompanhar este aglomerado, que chamaremos aqui de Arranjo Produtivo de Açaí da Região do Grão-Pará (APLAçaí-GrãoPará), 
com os mesmos instrumentos de investigação utilizados em 2002, em duas outras pesquisas; em 2007 (NACIF, 2009) e em 2010 (COSTA et al., 2011). A tríade de estudos oferece a possibilidade de análise da evolução do arranjo, sua constituição, situação e dinâmica, com informações que cobrem um período de nove anos.

Consideramos no estudo a acepção de Arranjos Produtivos Locais (APL) que orienta o programa de pesquisa da RedeSist (CASSIOLATO; LASTRES, 2003). No tratamento de sua dinâmica, porém, operaremos um esquema analítico sintetizado na noção de regime de crescimento do APL.

A noção de regime de crescimento, desenvolvida originalmente pela Escola da Regulação Francesa (BOYER; PETIT, 1991), em convergências e complementaridades com programas de pesquisa pós-keynesianos e schumpeterianos, refere-se a um esquema analítico com o qual se discute, há tempos, padrões de crescimento de economias nacionais e, mais recentemente, de economias regionais (AMITRANO, 2010a; LOURENÇO et al., 2012; SETTERFIELD, 2010). Nessa perspectiva, um regime de crescimento se decompõe em três fundamentos: 1) o regime de produtividade (RP), que explicita os determinantes do progresso técnico e da acumulação; 2) o regime de demanda (RD), que descreve os determinantes dos componentes da demanda agregada; e 3) um regime institucional, que expressa as mediações que assumem na definição do RD e do RP, naquele tempo e lugar, as formas institucionais que organizam as necessidades preponderantes do capitalismo: o mercado - os padrões de concorrência intercapitalista - e as grandes referências regulatórias do trabalho e da moeda.

Para ajustar essas noções à compreensão de APLs, um esforço teórico é necessário. A isso se dedicará a seção 2 do artigo, que também discutirá os desafios metodológicos enfrentados, considerando as exigências teóricas do exercício e o tipo de dados disponíveis a partir das diferentes pesquisas empreendidas. Na seção 3, discute-se brevemente a dinâmica recente de crescimento do APL. Na seção 4 se discutirão os resultados empíricos num esforço de demonstração das características do regime de crescimento. As seções 5 e 6, por fim, discutem o regime de demanda e o regime institucional do APLAçai-GrãoPará. Ao final, serão apresentadas as conclusões finais.

\section{Considerações Teóricas e Metodológicas}

Arranjos Produtivos Locais (APL) são aglomerações produtivas resultantes das interações sistêmicas entre empresas que numa mesma localidade produzem um bem ou serviço, ou uma categoria específica de bens ou serviço; das relações dessas empresas com seus fornecedores e clientes e com o ambiente institucional e natural estabelecido (CASSIOLATO, LASTRES, STALLIVIERI, 2008; CASSIOLATO, LASTRES, 2003). 
Um Arranjo Produtivo Local (APL) existe como parte de uma divisão social do trabalho estabelecida em nível extralocal, nacional e mundial. Emerge, portanto, nas relações sistêmicas primordiais estabelecidas entre as condições produtivas locais com dois tipos de estruturações distintas, porém intimamente articuladas, vigentes em sistemas superiores: um APL emerge geneticamente vinculado a trajetórias tecnológicas orientadas ao seu produto, que organizam as relações técnicas de produção nele prevalecentes; um APL é, ao mesmo tempo, expressão de cadeias de valor que organizam as relações sociais, de produção e de transação (as relações de seus agentes entre si e com os agentes externos) e, com isso, a distribuição do excedente nele gerado.

\subsection{Referências Estruturais para Avaliação do APL}

Trajetórias tecnológicas, para Dosi (2006, 22-23), são padrões de atividades que resolvem, com base em um paradigma tecnológico, os problemas produtivos que confrontam os processos decisórios das empresas, estas entendidas como sistemas abertos (PENROSE, 2006; CHANDLER, 1962; ROSENBERG, 2006; PORTER, 1989), em contextos específicos, nas dimensões econômica, institucional e social. Considerando o elevado nível de incerteza que cerca a adoção de tecnologias, o ambiente institucional assume particular relevância na configuração de trajetórias, desde o interesse econômico das organizações, passando pelas respectivas histórias na formação de expertise, até variáveis institucionais stricto sensu, como disposições planejadas de agências públicas e interesses geopolíticos (DOSI, 2006, 24-25).

As trajetórias tecnológicas conformam as interações primárias que definem as condições técnicas de operação, e, portanto, os níveis de produtividade física alcançados nos processos produtivos. Acresce que as trajetórias tecnológicas se movem por decisões dos agentes orientados por rentabilidade, pelas expressões pecuniárias do que lhes cabe do excedente material, definidas, em última instância, por cadeias de valor - estruturações sistêmicas que realizam nos mercados os produtos das trajetórias tecnológicas como mercadorias e medeiam seus custos.

Nas cadeias de valor operam as particularidades do contexto econômico "que agem como seletores definindo mais ou menos precisamente o trajeto concreto seguido no interior de um conjunto maior de possibilidades" (DOSI, 2006, 23). Desenvolvida pioneiramente por Hopkins e Wallerstein (1986, 189), a noção de cadeia de valor comporta três dimensões: uma estrutura de insumo-produto articulando os elementos de determinação de custos e valorização pecuniária de excedente, desde os fatores das funções de produção, em que se incluem os salários e inputs produtivos, passando por uma sequência de atividades de formação de renda, até o consumo final; uma territorialidade que determina e identifica a 
dispersão ou concentração geográfica da produção de matérias primas e produtos acabados, bem como a localização de redes de comercialização; e uma estrutura de governança - uma dimensão institucional, estruturada hierarquicamente ou em rede, que determina como os recursos humanos, materiais e financeiros, bem como o lucro, são alocados e circulam no interior da cadeia (APPELBAUM; GERIFFI, 1994a, 42).

\subsection{Regime de Produtividade, Regime de Demanda, Regime Institucional}

Arranjos Produtivos Locais (APLs) emergem das operações, em lugares definidos, de trajetórias tecnológicas, e das cadeias de valor a elas associadas, para produção e distribuição de um item da divisão social do trabalho. As diferentes condições da operação produtiva, dadas pelo modo de realização local das trajetórias tecnológicas por ele constituída, definem o regime de produtividade de um APL, que pode ser avaliado considerando dois processos que Dosi $(1988,130)$ chamou de "eficiência de crescimento" e "eficiência schumpeteriana". No primeiro caso, trata-se de eficiência demonstrada em ganhos de escala; no segundo caso, eficiência derivada de capacidades concretas baseadas em conhecimento, aprendizado e interatividade de escopo particular, internalizados nas empresas ou como externalidades do local, a serem desvendadas em sua constituição e sistematicidade como sistemas de inovação nacionais (FREEMAN, 1988), regionais (COOKE; MORGAN, 1998; LUNDVALL, 2002) ou locais (CASSIOLATO; LASTRES, 2003).

Por outro lado, as condições de interação do APL com as cadeias de valor de que faz parte definem seu regime de demanda. Aqui importam as formas de organização dos mercados, tanto de trabalho e insumos tangíveis e intangíveis, quanto de produtos: se mediante competição ou cooperação, ou, em estratégias compostas, de competição na repartição dos resultados e cooperação para atingir determinados objetivos (NALEBUFF, BRANDENBURGER, 1996, p. 28); se mediante cadeias muito longas (que incluem mercado mundial), longas (mercado nacional) ou curtas (mercado local); se submetido a assimetrias desfavoráveis, que o fazem um tomador de preços; ou, ao contrário, capaz de garantir algum grau de monopólio no estabelecimento dos preços; enfim, se capaz de garantir margens "normais", satisfatórias ou excepcionais. Parte, ainda, do regime de demanda, a maneira como se forma poder de compra orientado para os produtos do APL em questão, o que define como a demanda exógena se relaciona com a produção do APL.

Por fim, o regime institucional do APL se conforma na interação entre o ambiente institucional, cultural e político propriamente local, com elementos da governança da trajetória tecnológica do seu produto final, tal como aportam ao local, com elementos da governança das cadeias de valor correlatas e, ainda, com 
elementos da governança das trajetórias e cadeias de valor que provêm os meios endógenos e exógenos ao local.

\subsection{Regime de Crescimento}

Um APL encontra na interação entre seus regimes de produtividade e de demanda, com o suporte das respectivas mediações institucionais, as condições para o crescimento por causação circular e cumulativa (MYRDAL, 1957): se o regime de demanda garante a internalização de níveis elevados de excedente, este poderá se tornar base de investimentos com impacto positivo na produtividade e resultar, portanto, na geração adicional de valor excedente, e assim por diante. Nisso teríamos o regime de crescimento do APL (BOYER; PETIT, 1991).

\subsection{Considerações Metodológicas}

Os dados aqui utilizados resultaram de pesquisas realizadas em 2002, 2008 e 2011, referentes às condições encontradas nas empresas do APL nos anos imediatamente anteriores, respectivamente, 2002, 2007 e 2010. As pesquisas de 2008 e 2011 utilizaram amostras que seguiram dois princípios: para garantir comparabilidade entre elas e a pesquisa de 2002, resguardou-se a "regra" amostral da primeira pesquisa quanto ao erro e, para ter capacidade de contraste entre empresas "antigas" e "novas", adotaram-se procedimentos de segmentação de todas as amostras, do que fez parte a observação dos destinos das empresas ausentes na amostra de cada pesquisa, considerando as pesquisas anteriores. Confiando no princípio amostral, a comparação entre os resultados médios das amostras no tempo permite inferir sobre a evolução do conjunto das empresas do APL, como unidade de análise.

A análise segmentada, por seu turno, permite contrastar a evolução das empresas "novas" e "antigas", permitindo inferir sobre importantes fundamentos da dinâmica do arranjo no curto, porém, para o aglomerado, agitado período tratado. Assim, as amostras $n=27$ empresas na primeira pesquisa e $n=17$ na segunda e na terceira, foram divididas do seguinte modo: i) um grupo de 7 empresas presentes em 2002, 2007 e 2010 designado "consolidadas"; ii) um grupo de 14 empresas só presentes em 2002, fechadas quando da realização das pesquisas seguintes, chamado de "fracassadas da primeira geração"; iii) um grupo designado "fracassadas da segunda geração" composto de 6 empresas presentes em 2002 e 2007, porém ausentes da amostra e fechadas em 2011, e 1 empresa só presente em 2007; iv) um grupo de 3 "emergentes", presentes em 2007 e 2010 e v) um grupo de empresas "recentes", composto de 7 empresas só presentes em 2010. Em relação às amostras: em 2002, 7 "consolidadas”, 14 "fracassadas da primeira geração" e 
6 "fracassadas da segunda geração"; em 2007, 7 consolidadas, 7 "fracassadas da segunda geração", 3 "emergentes”; em 2010, 7 “consolidadas”, 3 "emergentes” e 7 "recentes".

\section{Crescimento do APLAçaí-GrãoPará}

Tamanho e crescimento do APL se expressam nas variáveis indicativas da capacidade produtiva e da capacidade de acesso a poder de compra. A produção física agregada (Produção - P) do produto final (polpa de frutas) das empresas do aglomerado constitui proxy da primeira e a receita total respectiva (Valor Bruto da Produção - VBP), da segunda dessas variáveis.

A Produção (P) multiplicou-se por cinco de 2002 a 2007, saindo de 10,3 mil toneladas para 51,6, caindo para 26,5 mil toneladas até 2010 (Gráfico 1). No primeiro período isso representou crescimento à explosiva taxa de $38,0 \%$ a.a.; entre 2002 e 2010, um crescimento à taxa média de $12,5 \%$ a.a.

$P$ indica a capacidade produtiva total, resultado da extensão da base produtiva do APL e do grau de intensidade do trabalho, isto é, do nível de produtividade nele verificado. Uma proxy da extensão da capacidade instalada é o número agregado total de trabalhadores das empresas do APL (Trabalho - T). A Produtividade por Trabalhador é igual à relação entre Produção Total e o Trabalho aplicado $(p=P / T)$.

Gráfico 1 - Quantidade de empregados, quantidade produzida (t) e valor da produção (R\$1.000,00 de 2010) do APLAçaí-GrãoPará, 2002, 2007 e 2010.

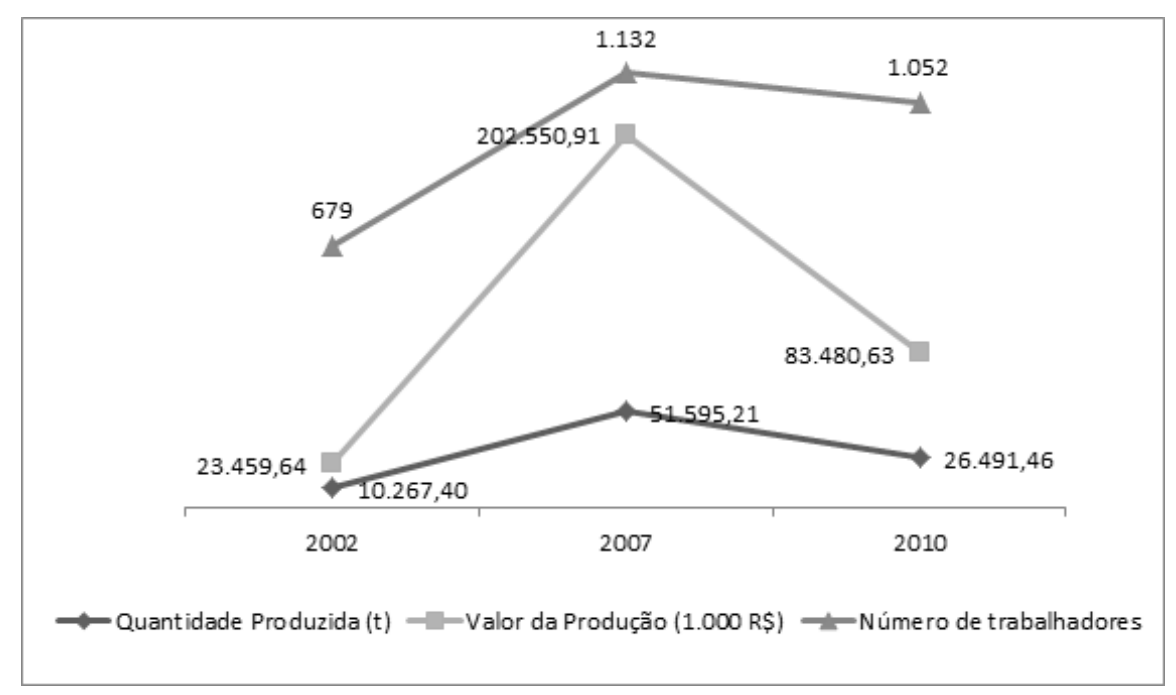

Fonte: Elaboração própria com base em pesquisas de 2003, 2011 e Nacif (2009). 
$T$ quase duplicou no primeiro período, crescendo de 679, em 2002, para 1.132 trabalhadores em 2007 - uma taxa anual média de 10,8\% a.a.. Em 2010 caiu ligeiramente para 1.052 trabalhadores, conforme Gráfico 1, o que levou a uma taxa média para todo o período de 5,6\% a.a. Por sua vez, p multiplicou-se por 3, de 15 para 46 toneladas de polpa por trabalhador, no primeiro interregno, garantindo, nessa fase, uma taxa de crescimento de 25,1\% a.a., dado que cai para 25 toneladas por trabalhador em 2010. O crescimento anual médio de p entre $2002 \mathrm{e}$ 2010 foi da ordem de 6,6\%.

Em síntese: na primeira fase, o crescimento à taxa de $38 \%$ a.a. na capacidade produtiva total $(P)$ tem 10,8 pontos percentuais (ou 28\% da taxa total, de $38 \%$ ) explicados pelo crescimento extensivo do APL (T) e 25,1 pontos percentuais ( $65 \%$ do total) explicados pelo aumento da produtividade do trabalho ( $p)$. A diferença de 2,7 pontos percentuais, equivalente a $7 \%$ da taxa total, resulta do efeito composto do crescimento extensivo e intensivo. No período por inteiro, o crescimento de $P$ a $12,5 \%$ a.a. teve 5,6 pontos percentuais ( $45 \%$ do total) devidos ao crescimento $\mathrm{T}$ e 6,6 pontos (53\% do total) devidos à variação de $p$.

Olhando para qualquer extensão do tempo, esses resultados apontam para ganhos significativos de capacidades que ocorreram no arranjo (mais no primeiro período, quando, a julgar pela relativa inelasticidade do número de trabalhadores entre 2007 e 2010 em relação às demais variáveis, a capacidade instalada do APL foi atingida), os quais deverão ser esclarecidos na definição de seu regime de produtividade.

A capacidade de acesso do APL a poder de compra tem como proxy o Valor Bruto da Produção Total (VBP), equivalente à receita agregada total das empresas (todos os valores corrigidos para 2010). O VBP multiplicou-se por 8,6, de R $\$ 23,5$ para $R \$ 202,2$ milhões de reais entre 2002 e 2007 - crescimento a 53,8\% ao ano. Como no caso da produção, um forte recuo para $\mathrm{R} \$ 83,5$ ocorreu em 2010 , levando a uma taxa média para todo o período de $17,2 \%$.

O VBP resulta da multiplicação da produção total vendida, ou da demanda total atendida, ambas aqui consideradas igual a $P$, a produção total do APL, pelo seu preço implícito de mercado $(i=V B P / P$, de modo que $V B P=P . i)$. $\mathrm{O}$ crescimento de $\mathrm{P}$ já mencionado anteriormente. Por seu turno, i cresceu significativamente, saindo de $R \$ 2,3$ para $R \$ 3,9$ entre 2002 para 2007, caindo a $R \$ 3,2$ mil em 2010: taxa de $11,2 \%$ a.a. no primeiro período e de 4,1\% a.a. para todo o período.

Assim, o crescimento do VBP no primeiro período se explica pelo crescimento de $P$, da demanda atendida, como já se comentou, em 38,3 pontos percentuais (71,3\% da taxa de crescimento total) e 11,2 pontos percentuais $(20,8 \%$ do crescimento total) do crescimento de $i$; para o período por inteiro, $P$ explica $73 \%$ e i $23 \%$ da taxa de crescimento total de $17.2 \%$ a.a. do VBP. Tanto a forte expansão da demanda, quanto o persistente e importante crescimento positivo do preço 
implícito, são fenômenos essenciais a serem esclarecidos no contexto do regime de demanda do APL.

\section{O Regime de Produtividade do APLAçaí-GrãoPará}

O crescimento do APL, como já se comentou, fez-se com produtividade do trabalho crescente. Este é o fenômeno síntese do Regime de Produtividade (RP) que se esclarece por três tipos de eventos: o desenvolvimento da trajetória tecnológica que fundamenta o APL (a isso dedicaremos a seção 4.1), a intensidade de internalização desse desenvolvimento nas empresas (ou, visto por outra ótica, a participação das empresas nesse desenvolvimento) pela via das inovações (seção 4.2), a formação de economias de escala internas às empresas (seção 4.3) e os ganhos derivados de externalidades associadas a sinergias resultantes a) do aprofundamento da divisão social do trabalho no quadro do APL por inteiro, e b) derivado de esforço de governança que articula capacidades conjuntas para resolução de problemas produtivos ou transacionais do APL. Este artigo tratará apenas do segundo movimento, na seção 4.3.

\subsection{A Trajetória Tecnológica que Fundamenta o APL}

A economia do açaí é ancestral na Região do Grão-Pará. O preparo do "vinho" do açaí era tarefa doméstica, consistindo no despolpe por amassamento manual feito pelas donas de casa, mucamas e domésticas. Na Belém da segunda metade do século XIX, em plena vigência do "ciclo" da borracha, tal tarefa constituiu profissão de negras e mulatas no atendimento da demanda, já importante, da grande cidade. Por essa época, em 1881, desenvolveu-se, para o amassamento do açaí, uma aplicação da máquina a vapor que, todavia, não se afirmou como processo dominante (PONTE, 2013). Mais de meio século depois, nos anos quarenta do século XX, foi desenvolvida a máquina elétrica para bater açaí, estabelecendo o princípio tecnológico para processamento que vigora até hoje: o princípio do atrito (fase de processamento 1: os frutos do açaí postos em um cilindro de aço são submetidos, a seco, a atrito entre si e com palhetas presas a um eixo vertical movido por um motor elétrico), adição de água (fase 2: a água é progressivamente adicionada à polpa) e filtração (fase 3: o açaí desce gradativamente por gravidade e passa através de uma peneira) (ROGÉZ, 2000, 107).

Essa tecnologia, adotada desde então entre os "batedores" artesanais de açaí, a que nos referimos na introdução, manteve-se como core da produção industrial do açaí, ocorrendo, não obstante, desenvolvimentos tecnológicos fundamentais, porém incrementais. 
As inovações ocorreram em torno de três núcleos principais, compondo, no que se refere aos processos produtivos, uma trajetória tecnológica própria em afirmação no APL de Produção Industrial de Polpa: um relativo ao tamanho dos equipamentos, outro, à integração das máquinas em um sistema, e, um terceiro, à agregação de operações e instrumentos suplementares.

No que tange ao tamanho dos equipamentos, as máquinas cilíndricas cresceram em capacidade, de um máximo de 12 quilogramas, que eventualmente se encontravam entre os "batedores" artesanais (a média, como já se mencionou, era de 2,9 quilogramas por batida), para até 70 quilogramas de frutos em um ciclo de processamento nas empresas industriais. Uma variação de tamanho das máquinas proporciona escala às operações de alimentação de matéria-prima, de limpeza das máquinas entre ciclo de processamento e de recolhimento de detritos. Entretanto, a eficiência não cresce linearmente com o tamanho do cilindro e a potência do motor, como indicaram pesquisas laboratoriais. ${ }^{1} \mathrm{Na}$ prática, as máquinas adotadas se situam em tamanho entre 30 e 42 quilogramas por batida.

As máquinas são articuladas em um sistema com formas mecânicas e sincronizadas de alimentação da matéria-prima, de adição de água e recolhimento de polpa e detritos (a grande massa de caroços, por exemplo). Assim, pode-se reduzir a participação humana nessas operações, mas se mantém, ao mesmo tempo, o comando e o controle de processos cruciais, particularmente na fase dois do núcleo tecnológica descrito anteriormente. O controle se faz, agora, para um set de máquinas, de modo que tanto maior esse conjunto, maior a produtividade por trabalhador. O espaço de elevação da produtividade resulta da conjugação de máquinas em módulos administráveis por um mesmo trabalhador, ou grupo de trabalhadores, e seria diretamente proporcional ao tamanho desses módulos (um módulo de dez máquinas de mesma capacidade média dos batedores, conjugadas, poderia elevar a produtividade média por trabalhador por dez, de 0,877 para 8,77 quilogramas de polpa; se essas máquinas dobram de tamanho, a produtividade alcançaria 17,5 quilogramas por trabalhador). No momento atual, encontram-se módulos que variam entre 10 e 12 máquinas, com capacidades médias entre 30 e 42 quilogramas. A esse núcleo central de processos são agregadas:

a. A montante: i) operações de limpeza e tratamento sanitário com ênfase em aeração, lavagem; ii) branqueamento; e iii) amolecimento: a imersão dos frutos em água morna $\left(35-40^{\circ} \mathrm{C}\right.$ ) por 20 minutos (em média) facilita o desprendimento do pericarpo.

b. A jusante: operações de envasamento mecânico e posterior congelamento i) rápido, em que o produto embalado é instalado em uma Câmara de Congelamento $\mathrm{a}-35^{\circ} \mathrm{C}$ por até 24 horas, até que todo o conteúdo esteja

$1 \quad$ Hervé Rogez, em entrevista concedida a Francisco de Assis Costa. Belém, 10 de agosto de 2017. 
devidamente congelado; e ii) o produto já congelado é levado para a Câmara Fria $\left(-18^{\circ} \mathrm{C}\right)$, onde é estocado.

Quanto aos produtos, a trajetória dominante mantém as linhas que já existem nos mercados interno e externo, destacando-se o mix de açaí, ${ }^{2}$ com inovações incrementais na produção de energéticos de açaí, de suco de açaí em embalagens tetra-pack e de suco de açaí clarificado. A produção de açaí liofilizado apresenta-se como um horizonte observado com interesse, uma vez que a liofilização do açaí é de enorme eficiência, tanto pela preservação dos nutrientes da fruta quanto pela otimização do custo de estocagem do produto. Ademais, o açaí em pó guarda uma grande versatilidade, podendo compor bebidas energéticas, iogurtes, barras de cereais, sorvetes, milk shakes, produtos cosméticos, etc., assim como cápsulas de suplemento alimentar.

\subsection{Inovação Tecnológica}

As empresas internalizam os elementos e procedimentos da trajetória tecnológica em processo de afirmação em um APL pelos seus investimentos em inovação de produto e, principalmente, de processo. O Gráfico 2 apresenta um Índice de Inovação Total para as inovações de produto e de processo. O IIT representa a relação entre oportunidades realizadas e o total de oportunidades de inovação, isto é, número de empresas vezes o total de formas de inovação. As empresas do APLAçaí-GrãoPará apresentaram muito baixa disposição ou capacidade para a inovação tecnológica em 2002, quando o IIT foi de $10 \%$ para inovação de produto e $20 \%$ para inovação de processo: isto é, de todas as "oportunidades", ou das "possibilidades" de inovar, apenas $10 \%$ e $20 \%$ teriam sido realizadas no APL respectivamente para desenvolvimento de produto e de processo. Em 2007, o índice quadruplicou, praticamente, nas duas formas de inovação, proporção que basicamente se manteve em 2010.

2 O mix de açaí consiste em uma espécie de sorvete de açaí pasteurizado e misturado com outras frutas (banana, morango, guaraná) e, às vezes, com granola, e é comercializado em potes de 500 . 
Gráfico 2 - Índice de inovação total por formas de inovação tecnológica do APL, 2002, 2007 e 2010

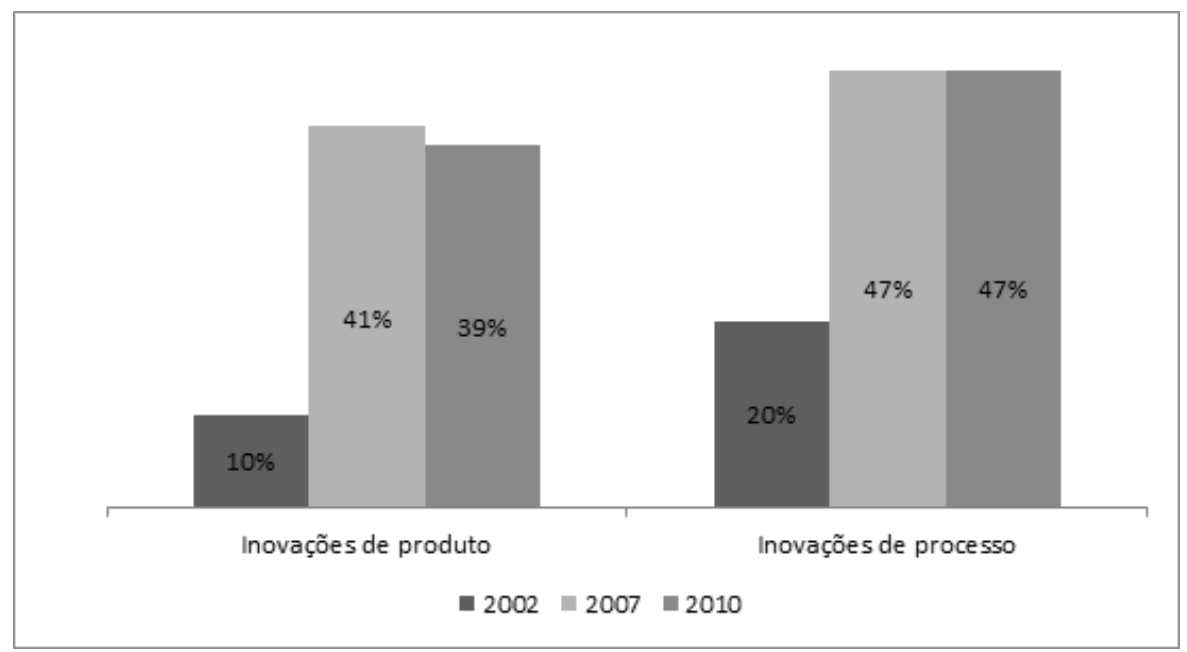

Fonte: Elaboração própria com base em pesquisas de 2003, 2011 e Nacif (2009).

Consoante com isso, as principais atividades de inovação encontradas na última pesquisa foram treinamentos voltados a novos produtos ou processos $(65 \%$ das firmas), implantação de projetos industriais associados a novos produtos ou processos (65\%) e aquisição de máquinas e equipamentos tecnologicamente mais avançados (53\%), além de novas formas de comercialização e distribuição de produtos novos ou significativamente melhorados (47\%).

O treinamento da mão de obra foi, por excelência, a forma de capacitação de recursos humanos de maior importância na perspectiva dos empresários do arranjo: treinamento interno (82\%), ao lado de cursos técnicos realizados dentro e fora do arranjo, além da contratação de técnicos ou engenheiros de empresas fora do APL. Isso converge com as fontes declaradas de absorção e ampliação de conhecimento, dominantemente fontes internas, com 59\% das empresas tendo na área de produção o lócus primordial do aprendizado, inerentemente tácito e learning by doing.

Tais resultados nos oferecem um interessante momento de reflexão. Edith Penrose sublinha a existência de nexos causais entre recursos, capacitações e vantagens competitivas das empresas. Para a autora, o crescimento rentável das firmas dependeria da dotação de recursos, a qual pode ser ampliada, por suposto, via mercado. Todavia, na sua perspectiva as firmas podem gerar valor econômico não apenas da posse desses recursos, mas, também, e, não raro, sobretudo, do desenvolvimento desses recursos, da sua conversão, pela gestão interna, em novas capacidades que geram oportunidades produtivas de crescimento e inovação (ver 
formulações originais em Penrose, 2006 e as avaliações recentes de Thompson e Wright, 2005 e Kor e Mahoney, 2004). A ênfase aqui verificada na geração de capacitações entre trabalhadores e técnicos parece corroborar essa perspectiva no APL, oferecendo, ademais, uma hipótese plausível para a rigidez no número de empregados comparativamente às variáveis de produção total, já comentada na seção 3: enquanto entre 2007 e 2010 a produção reduziu-se à metade, o número total de trabalhadores se manteve praticamente estável, um comportamento de retenção de ativos.

\subsection{Inovação e Mobilidade Estrutural do APL}

O papel da inovação tecnológica cresceu substancialmente no período, principalmente na primeira fase aqui tratada. Isso posto, uma questão que se coloca é a seguinte: em que medida a mudança de patamar no nível de adoção e na efetividade das inovações se associa a dinâmicas próprias de concorrência entre empresas que já se encontravam no APL, umas internalizando incrementalmente tecnologias superiores e outras não? Ou é a entrada de novas empresas tecnologicamente mais avançadas o que altera o desempenho da média? O que se vê seria uma reafirmação da tendência de concentração e centralização comandada pelas empresas que, inovadoras, permanecem em companhia de novas que já chegam ao APL tecnologicamente superiores - umas e outras deslocando as empresas incapazes de inovar, as quais fenecem, de modo que cresce ao final a proporção das que inovam?

Para responder a essas questões, recorremos a uma análise baseada nas amostras segmentadas que apresentamos em 2.4. Uma leitura das suas performances em relação à inovação (ver Gráfico 3) levam-nos ao seguinte:

1. As empresas que declararam inovar menos em 2002 (apresentaram o menor IIT), ou saíram definitivamente do APL, ou se encontravam paralisadas em 2007, compondo o grupo de "fracassadas de primeira geração";

2. O grupo de empresas que mais inovou no primeiro momento (quando o IIT de todo APL era muito baixo), tornou-se o que menos inovou em 2007 (quando o grau de inovação esteve bem alto). Assim procedendo, deixou de existir em 2011, formando o grupo de "fracassadas de segunda geração";

3. As empresas "consolidadas" tiveram IIT mediano, porém relativamente constante nos três momentos pesquisados;

4. As "emergentes" apresentaram o IIT mais alto encontrado em 2007 e 2010;

5. As "recentes" apresentam IIT equivalente às consolidadas em 2010. 
Gráfico 3 - Índice de inovação total das empresas do APLAçaí-GrãoPará por grupo amostral de acordo com o Status de Mobilidade e Permanência em 2002, 2007 e 2010

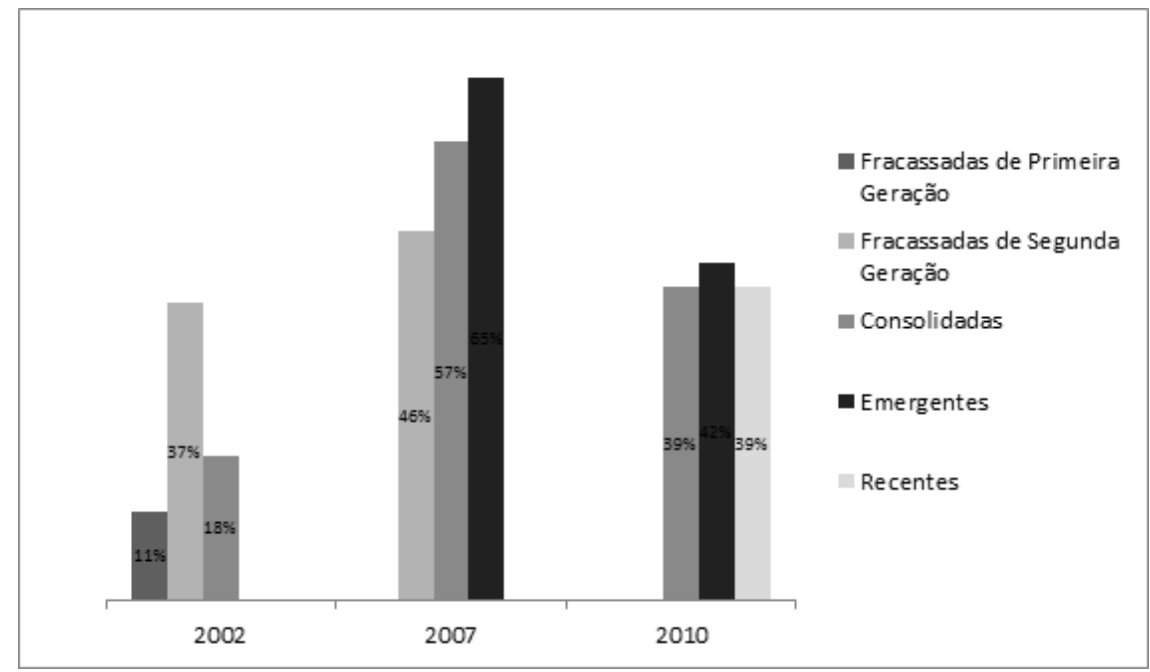

Fonte: Elaboração própria com base em pesquisas de 2003, 2011 e Nacif (2009).

\subsection{Ganhos de Produtividade e Economias de Escala nas Empresas}

As empresas do APL vêm operando em convergência orientada pela trajetória tecnológica descrita. As que perdem o timing no que se refere às inovações necessárias, ficam para trás. Às que permanecem, a trajetória tecnológica tem garantido crescimento com produtividade crescente, por economias de escala significativas.

É o que se demonstra no Gráfico 4: para o total da amostra, a produtividade média por trabalhador (os valores de $p$ para cada pesquisa) cresceu com a escala média das empresas (e $=P / n$, em cada pesquisa). Entre o ponto mais baixo e o mais elevado da curva, para cada ponto percentual de crescimento na elevação da escala cresceu 0,28 ponto na produtividade do trabalho (ver Gráfico 4; os valores no eixo horizontal não estão distribuídos em escala regular, mas em função dos valores reais das escalas de produção dos grupos de empresa e do total de empresas).

Há histórias diferentes entre os grupos de empresas, no que se refere à composição do trajeto escala-produtividade do APL: o grupo das "consolidadas" apresentou ganhos de escala superiores à média e bem superiores às "fracassadas de segunda geração", até o ponto em que as "emergentes", com ganhos de escala bem mais elevados que todos os demais, começam a influenciar a média. Na prá- 
tica do processo, isso significa que as "fracassadas de segunda geração", com baixa capacidade para a inovação, operando em escala que só lhe permitia produtividade inferior, foram substituídas pelas "emergentes", empresas de escala e nível de produtividade sem precedente no APL. Assim, empresas com escala média de 1,7 mil t/a foram substituídas por empresas com 4,8 t/a de produção de polpa de frutas, de modo que 6 empresas com capacidade de produção conjunta de 10,2 mil t/a são substituídas por 3 empresas com capacidade de produção total de 14,3 mil t/a. As "consolidadas", por seu turno, mantêm-se, com escala crescente, agora com ganhos de escala inferiores à média. Verifica-se, ao fim e ao cabo, o processo de concentração, que Marx (1978) enunciava como inerente à produção capitalista. Em parte, como resultado do crescimento de parcelas de capital já presentes no nodo industrial do APL com níveis tecnológicos acima da média, em parte pela entrada de parcelas de capital (provindas da economia em geral, ou de outros APLs ou, ainda, de outros nodos do APL em questão) no nodo industrial do arranjo com capacidade igual ou superior à média preexistente, tem-se, por fim, um número menor de empresas produzindo um múltiplo das suas antecessoras - ou de suas versões originárias.

Gráfico 4 - Relação entre escala de produção das empresas e nível de produtividade do trabalho por grupo amostral por Status de Mobilidade e Permanência, 2002, 2007 e 2010

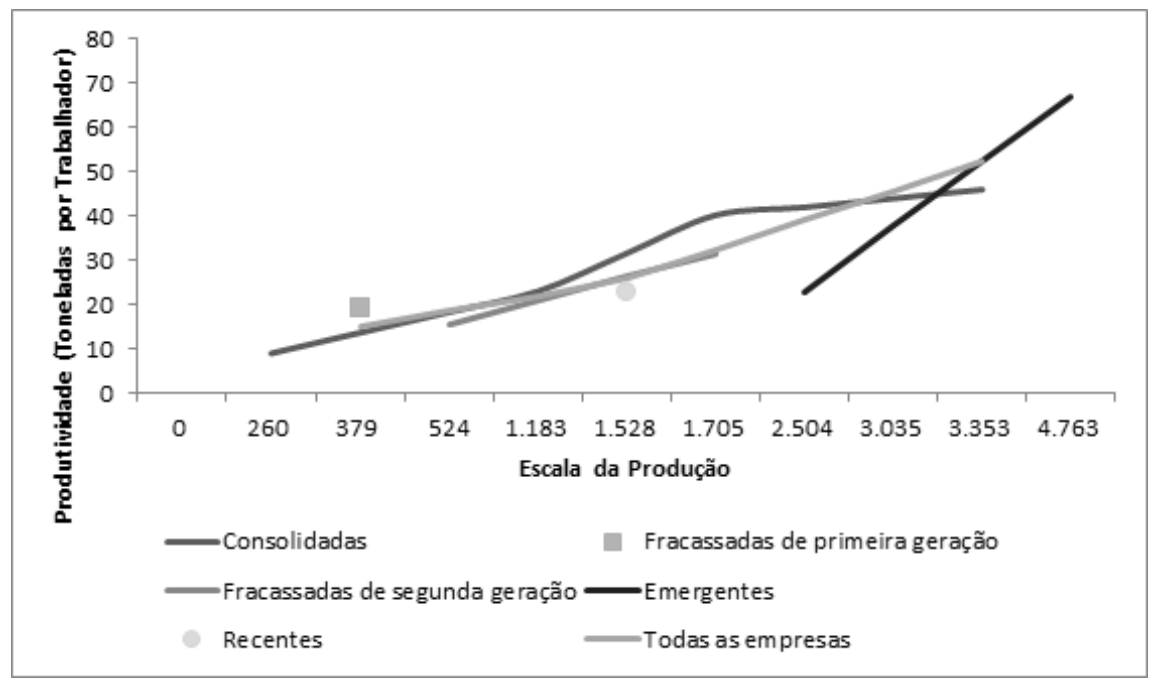

Fonte: Elaboração própria com base em pesquisas de 2003, 2011 e Nacif (2009). 


\subsection{Concentração e Cooperação}

Considerando os desenvolvimentos antes apresentados, uma questão se coloca: o avanço em tamanho e capacidade contou com ganhos associados à cooperação por parte das empresas? Ou prescindiu deles ou, ainda, os inibiu?

Uma primeira coisa a considerar é que o Índice de Cooperação Total (ICT), que relaciona as oportunidades realizadas com o total de oportunidades de cooperação (ver Gráfico 5), tem sido relativamente baixo: de 14\% em 2002, mantendo-se em patamar semelhante em 2007 e crescendo substancialmente para $20 \%$ em 2010. Ademais disso, ocorre o seguinte:

a) as empresas "fracassadas de primeira geração" apresentaram em 2002 o menor ICT médio;

b) as "fracassadas de segunda geração" apresentaram a segunda menor disposição à cooperação em 2002 e 2007;

c) as empresas "consolidadas" apresentaram em 2002 e 2007 a maior disposição à cooperação e, em 2010 ficaram ligeiramente abaixo das "emergentes";

d) as "recentes" apresentam ICT equivalente às consolidadas em 2010.

As principais formas de cooperação têm sido participação conjunta em feiras (importância crescente), reivindicações diversas (importância estável) e treinamento de mão de obra (importância crescente). Venda e compra conjunta são oportunidades de cooperação que vêm ganhando destaque, ao contrário do desenvolvimento tecnológico, de produtos e processos, que se apresentam como temas de menor e decrescente importância na cooperação. 
Gráfico 5 - Índice de Cooperação Total das Empresas do APLAçaí-GrãoPará de acordo com o Status de Mobilidade e Permanência em 2002, 2008 e 2010

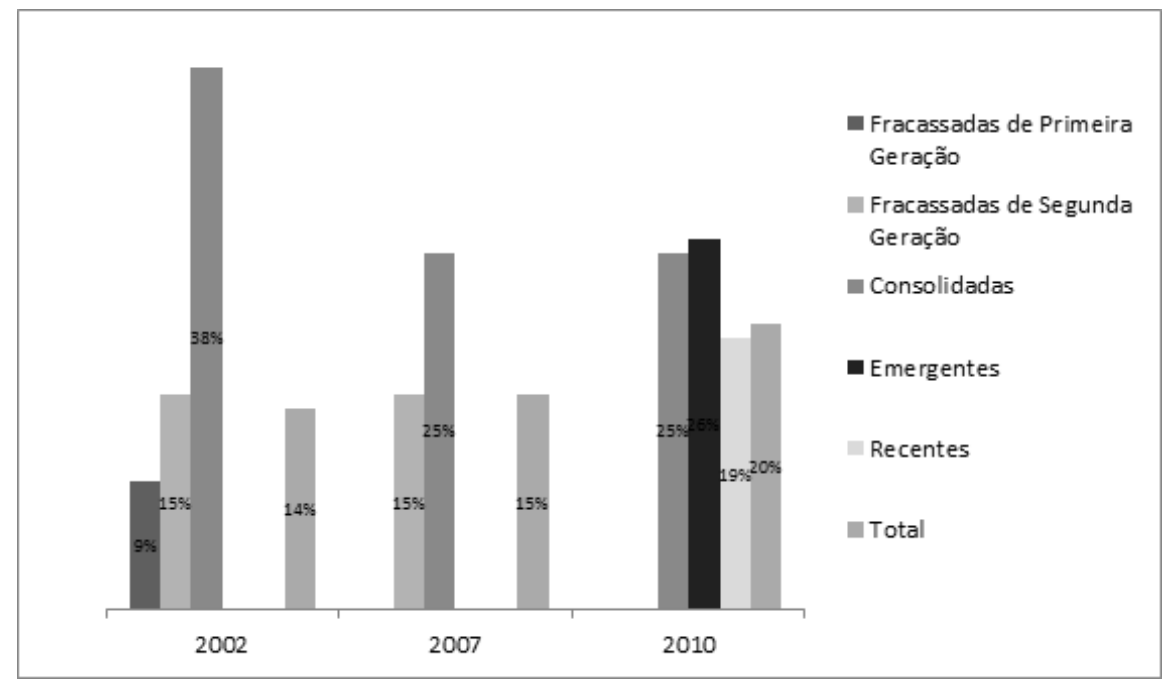

Fonte: Elaboração própria com base em pesquisas de 2003, 2011 e Nacif (2009).

\section{Regime de Demanda do APLAçaí-GrãoPará}

O crescimento é determinado pela demanda e o Regime da Demanda (RD), isto é, as condições de interação do APL com as cadeias de valor de que faz parte, é a descrição compreensiva da sua estruturação e dinâmica. A demanda efetiva orientada à produção do APLAçaí-GrãoPará é composta da demanda intermediária das indústrias de alimento e cosméticos e da demanda final de diversas formas de processamento para o comércio de varejo de consumo direto em forma de sorvetes e sucos.

\subsection{Preço Implícito e Evolução da Demanda}

O preço implícito dos produtos do APL cresceu no período investigado, como demonstrado na seção 3. O preço implícito de venda de um bem pode ser tomado como uma proxy do déficit ou superávit da oferta (produção atribuível não apenas ao APL em observação, mas ao conjunto dos APLs que produzem o bem em questão e seus substitutos) no atendimento da necessidade social por ele satisfeita. Se essa for maior ou menor que a produção ofertada, o preço implícito, respectivamente, crescerá ou reduzirá, indicando, no primeiro caso, demanda não atendida e, no segundo, demanda saturada. De modo que é justo presumir que a demanda (ou o poder de compra orientado ao consumo) dos produtos do arranjo 
cresceu no período em ritmo mais elevado que o da produção (P), apesar desta ter-se feito acelerada e com produtividade (p) crescente, como vimos na seção 4.

Em consonância com isso, a questão central na definição do Regime de Demanda do APL diz respeito à distribuição dos ganhos compostos de produtividade (seção 4) e de preço entre as empresas do APL e os diferentes atores que, nas cadeias de valor, organizam suas relações com os distintos mercados. Trata-se de verificar as condições de estabelecimento do lucro - do que depende o investimento, a acumulação e o crescimento do arranjo.

\subsection{Cadeias de Valor, Niveis de Mercado e Condições Primárias para o Lucro}

Nossos resultados permitem tratar aspectos críticos do estabelecimento do lucro em aderência com níveis de atuação das cadeias de valor. Indagando a cada firma quais as proporções da produção e do valor da produção vendidas nos diferentes níveis de mercado, conseguimos elementos para a montagem, para cada ano pesquisado, de uma agregação dos valores que transitam pelas cadeias de valor em quatro compartimentos correspondentes ao mercado local, ao mercado estadual, ao nacional e mundial e, para esses compartimentos, calcularam-se os preços implícitos de venda das empresas do APL e, por suposto, de compra dos atores das cadeias ali operantes.

Adicionalmente, indagou-se nas pesquisas sobre os preços de compra da matéria-prima. Conhecendo o preço da matéria prima para as indústrias e o respectivo preço de venda do seu produto final chegamos a uma taxa "base primária do lucro", $l=(i-m) / i$, onde $i$ é o preço implícito de venda e $m$ preço da matéria-prima. Consideramos $l$ um indicador das condições de lucratividade do APL.

Tanto a composição agregada das cadeias por compartimento, quanto a taxa "base primária do lucro" foram obtidas para o conjunto da amostra (ver Gráfico 6, para os três anos da amostra) e para os grupos segmentados (ver Gráfico 7, para 2010).

Tratando em conjunto esses resultados, chegamos às seguintes inferências: na sua primeira fase, o APL emergiu com a formação de cadeias de valor longas, por onde fluíam 79\% da produção de polpa de açaí: com destino nacional, 75\% e internacional, 4\% da produção; as cadeias curtas do mercado doméstico absorviam os demais $21 \%$ da produção, $13 \%$ para as áreas produtoras e $8 \%$ para o resto do estado; a base primária do lucro (l) era alta e não diferia fundamentalmente se uma empresa se orientava para um ou outro desses mercados: a variação de $l$ era ínfima, entre 55 e 56\% do valor bruto da produção, conforme o Gráfico 6.

Em 2007 se verificaram importantes mudanças na estrutura dessas cadeias, que em 2010 se consolidaram: neste último ano, as cadeias longas representavam 70\% da produção de polpa de açaí do APL, 37\% no mercado nacional (metade do 
que fora em 2002) e $33 \%$ no mercado mundial, que se tornou, assim, o segundo mais importante destino da produção do APL. As cadeias curtas do mercado doméstico crescem em importância para 30\% da produção, 18\% para as que operam nas áreas de produção e 12\% no resto do estado (cf. Gráfico 6).

Por sua vez, as condições primárias do lucro alteraram criticamente em todas as cadeias: as mais elevadas taxas $l$, de $19 \%$, após cortes pela metade, comparativamente a 2007, foram as das cadeias mais longas (mercado externo) e mais curtas (locais de produção). As que operam no mercado nacional, por sua vez, sofreram a mais drástica redução de $l$, alcançando ínfimos $2 \%$. A média, para todas as cadeias, em 2007, situa-se em torno de $41 \%, 20$ pontos percentuais abaixo da pesquisa anterior; e em 2010, novamente se reduz pela metade, comparativamente a 2007.

Gráfico 6 - Estrutura agregada das cadeias de valor e base de lucro por tipo de mercado: Total das empresas do APLAçaí-GrãoPará em 2002, 2007 e 2010.

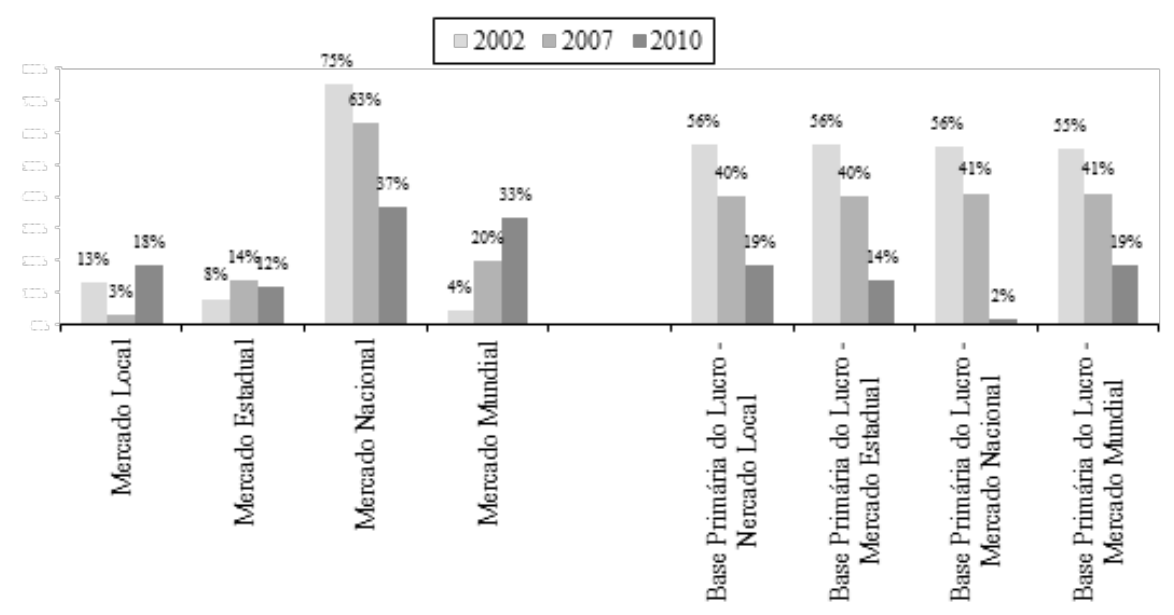

Fonte: Elaborado pelos autores com base em pesquisas de 2003, 2011 e Nacif (2009).

Tais movimentos se explicam basicamente por uma inflação da matéria-prima, cujo preço real, descontada a inflação da economia, cresceu entre 2002 e 2010 a 15\% a.a., enquanto o ritmo médio do crescimento dos preços dos produtos finais do APL se situou em torno de 5\% a.a.. As condições de funcionamento das cadeias de valor nos compartimentos de mercados são, por suposto, diferenciadas, de modo que foram distintas as relações entre as variações do preço da matéria prima e as variações no preço de mercado. A pior situação foi exatamente a das empresas que atuam no mercado nacional, para as quais a matéria-prima cresceu à mais elevada taxa, de $16 \%$ a.a., e o preço do produto final para as empresas do APL a meros 3\% a.a.. A mais favorável foi a das empresas que atuam no mercado mundial: estas foram também submetidas a preços da matéria-prima que crescem 
à mais alta taxa de $16 \%$ a.a., porém, auferiram preços pelos seus produtos finais que cresceram à taxa de 7\% a.a.. As condições locais desenham o segundo melhor contexto de operação do APL, com preços da matéria-prima que variam a 15\% a.a. e do produto final que variam a $5 \%$ a.a..

Assim, completamente de acordo com a expectativa teórica, as reduções da participação das cadeias de valor de alcance nacional no APL, verificadas em 2007 e em 2010, foram acompanhadas de profunda redução na perspectiva de lucro que elas ofereciam às empresas do APL.

As cadeias locais, ao contrário, combinam elevação da participação com comparativamente melhores condições para a realização de lucro. O mesmo se dá com as cadeias que alcançam o mercado mundial. As relações do APL com estas últimas têm crescido nos últimos anos, impulsionadas pelo crescimento da demanda de polpa de fruta e por uma crescente diversificação de produtos derivados do açaí, com a novidade da utilização crescente de componentes desse fruto para a composição de produtos da indústria alimentar e de bebidas em geral. Considerando informações pontuais prestadas nas entrevistas em relação ao faturamento e volume produzido pelas empresas que operam com exportação, chegamos a um preço médio aproximado de $\mathrm{R} \$ 3$ o quilograma do produto para exportação pelas empresas da amostra em 2010, o que representaria um faturamento de $R \$$ 30.890.000 ao ano, com um volume de produção total de 10.297.000 quilogramas. Volumes bem acima do estimado na pesquisa de 2002.

\subsection{Mobilidade Estrutural e Condições Primárias para o Lucro}

No novo cenário, as condições gerais se mostram diferentes para os diferentes grupos de empresas. Em 2010, as empresas "consolidadas" se situam em cadeias que, com exceção das que operam no mercado nacional $(l=5 \%)$, apresentam condições primárias para o lucro entre as mais elevadas $(22 \% \leq l \leq 28 \%)$. Por outro lado, elas atuam compondo posições em cadeias curtas e médias dos mercados local (25\%) e estadual (35\%), com cadeias longas, que alcançam o mercado nacional (28\%). Esta última posição merece destaque, considerando as aparentemente estreitas condições para o lucro acima observadas. A participação no mercado mundial, apesar de ter crescido, mostra-se a menor para as empresas consolidadas, apesar de apresentarem-se as cadeias que lhes permitem melhores condições primárias de lucro $(l=28 \%)$.

As empresas "emergentes" enfatizam as cadeias longas e muito longas, do mercado nacional (67\%) e mundial (25\%), negligenciando as do mercado estadual (7\%) e, ainda mais, as que operam em nível local. As condições primárias de lucro são melhores nos mercados estadual $(l=28 \%)$ e mundial $(l=27 \%)$, que no nacional $(l=12 \%)$. 
As empresas "recentes" são conectadas a cadeias exportadoras para o resto do mundo (67\%), não obstante há importante participação nos mercados locais (25\%). Deve-se notar, entretanto, em relação a esse grupo, que suas bases primárias de lucro são as mais baixas $(3 \% \leq l \leq 6 \%)$.

Gráfico 7 - Estrutura agregada das cadeias de valor e base de lucro em 2010 por grupos de empresas

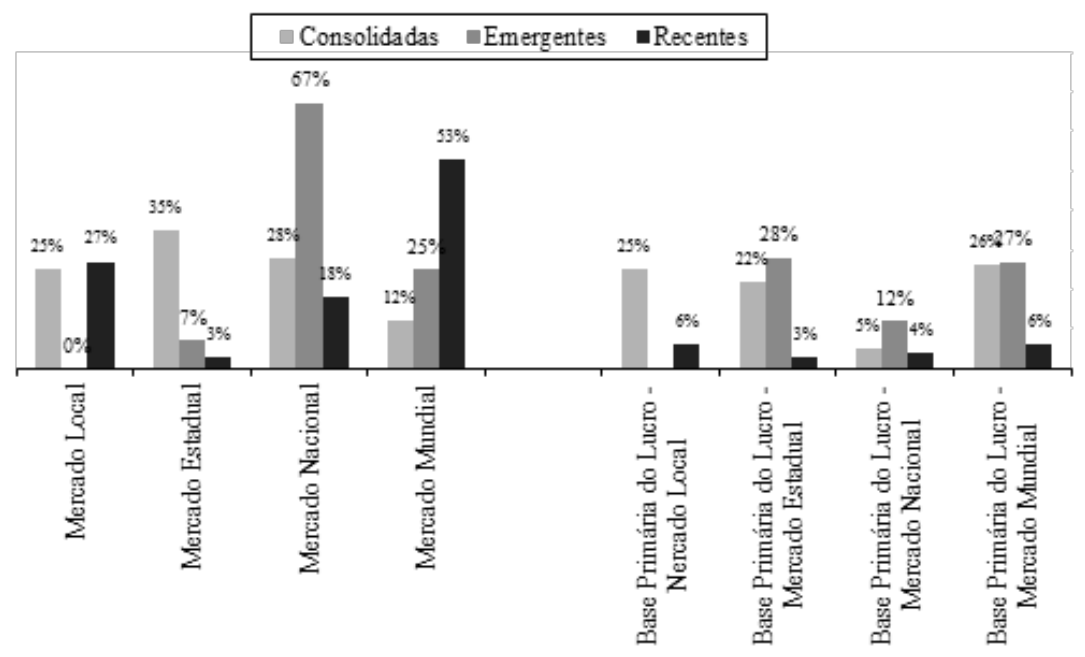

Fonte: Elaboração própria com base em pesquisas de 2003, 2011 e Nacif (2009).

\section{Regime Institucional do APL}

Há uma dimensão institucional do APL que atua em relação com os elementos definidores dos regimes de produtividade e de demanda. Essa conformação define o Regime Institucional do APL, a ser aprendido na interação entre si das suas empresas em busca de governança e gestão comum de problemas e soluções; na interação entre as empresas e o ambiente institucional, cultural e político local, e delas com os elementos da governança da trajetória tecnológica do seu produto final, tal como aportam ao local, e os elementos, ainda, da governança das cadeias de valor correlatas e das trajetórias e cadeias de valor que provêm os meios endógenos e exógenos ao local. As pesquisas desenvolvidas só permitem tratar as duas primeiras formas institucionais: as que regulam as articulações internas entre as empresas e entre estas e o ambiente institucional formalmente constituído. 


\subsection{Articulação e Participação em Políticas}

Na pesquisa de 2002 se constatava uma fraca articulação entre as empresas e entre estas e o ambiente institucional, ao mesmo tempo, porém, que se indicava o início de um processo de reversão desse estado de coisas, tanto por motivação interior ao próprio arranjo, que levava à formação de um grupo de representação sindical do APL na Federação da Indústria Paraense (FIEPA), quanto pela ação de organizações que procuravam levar avante uma estratégia de desenvolvimento que deslocava a ênfase em atores individuais em favor de redes de atores e aglomerações, como arranjos produtivos locais (COSTA, 2016; COSTA; ANDRADE; SILVA, 2010. De modo que, ao mesmo tempo em que se fortalecia o sindicato das empresas do APL, vários órgãos da administração estadual e federal pareciam iniciar um processo de articulação e fortalecimento institucional de uma rede de apoio em torno do arranjo, com participação ativa de organizações de pesquisa e fomento: Universidade Federal do Pará (UFPA), Universidade Federal Rural da Amazônia (UFRA), Embrapa/PA, Agência de Desenvolvimento da Amazônia (ADA), Serviço Brasileiro de Apoio às Micro e Pequenas Empresas (SEBRAE) e Secretaria de Agricultura do Estado do Pará (SAGRI).

Na pesquisa de 2011, entretanto, a percepção dos atores envolvidos é de desolação, tanto com o nível de organização do APL na FIEPA, quanto com a falta de interação institucional e políticas de apoio para o arranjo.

Com efeito, tomando, entre os subgrupos de empresas do APL já apresentados, o mais ativo nas relações institucionais, as "consolidadas", o Indicador de Acesso Institucional (IAI: número de oportunidades realizadas de participação em políticas dividido pelo número total de possibilidade), já baixo em 2002, com $31 \%$, caiu para 26\% em 2010 (ver Gráfico 8). Tanto as fracassadas de primeira como de segunda geração, tiveram bem pouco suporte institucional, assim como as "recentes" e, particularmente, as "emergentes".

Observando, agora, a participação das empresas nas políticas de diferentes níveis de governo e do Sistema S (ver Gráfico 9), destaca-se a presença contínua de políticas federais e de ações do SEBRAE acessadas pelas empresas "consolidadas" (verificando-se o crescimento da importância das primeiras, de $29 \%$ em 2002 para $43 \%$ em 2007 e 2010, e o decréscimo das últimas, de $71 \%$ em 2002 para $29 \%$ em 2007 e 2010) e a descontinuidade das políticas estaduais e municipais. As empresas recentes acessaram em $201030 \%$ das oportunidades de políticas oferecidas pelo governo federal e pelo SEBRAE. 


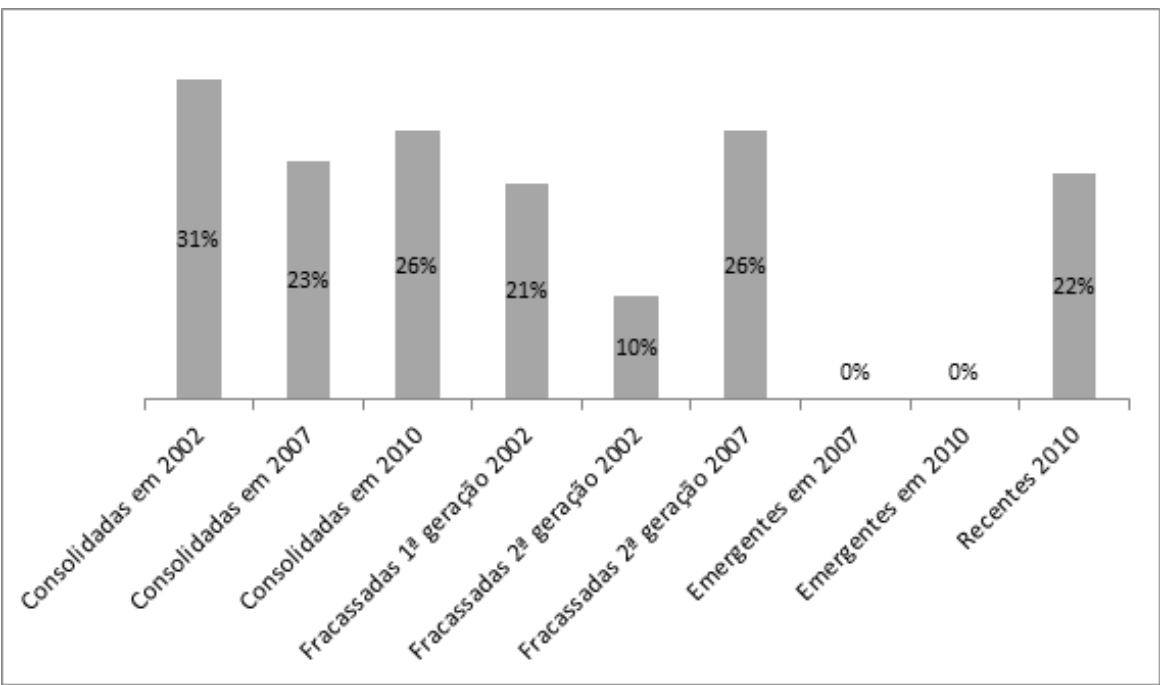

Fonte: Elaboração própria com base em pesquisas de 2003, 2011 e Nacif (2009).

Gráfico 9 - Participação no conjunto das políticas (\% das oportunidades) das empresas do APLAçaí-GrãoPará por nível de governo em 2002, 2007 e 2010

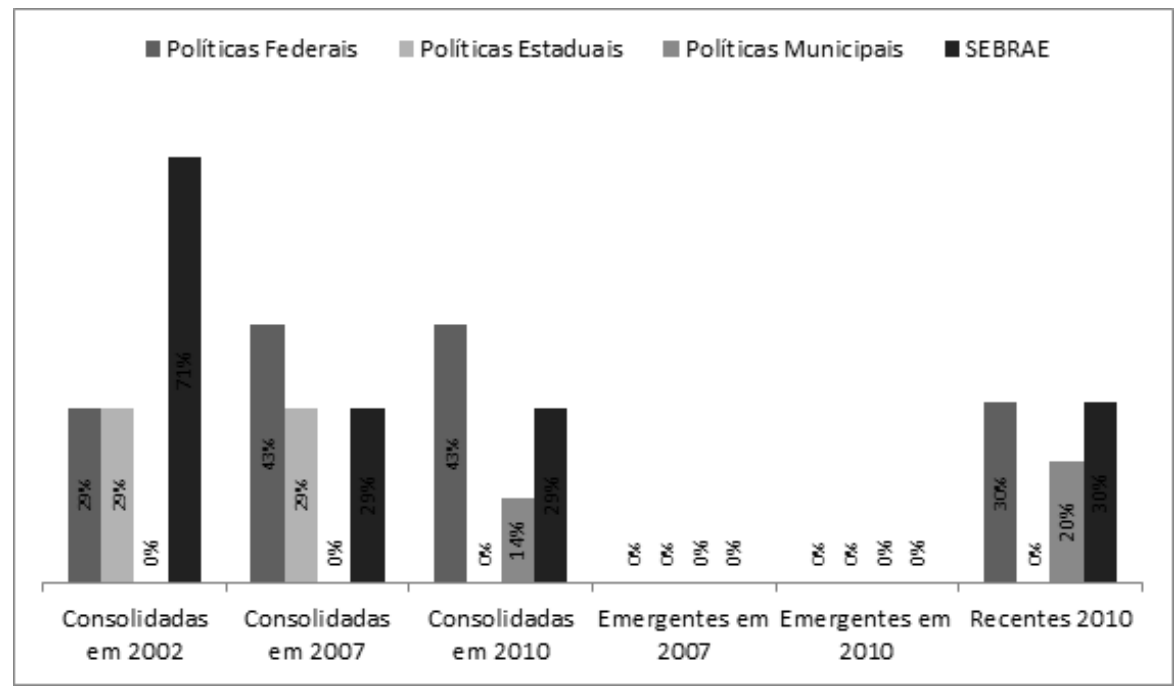

Fonte: Elaboração própria com base em pesquisas de 2003, 2011 e Nacif (2009).

Quanto à governança articulada pelos atores ligados diretamente à atividade produtiva principal do arranjo, a situação encontrada em 2010 não é diferente da 
de 2002. Nos dois momentos se afirma uma falta de percepção entre os empresários da importância da articulação institucional enquanto fundamento de uma estratégia de aumento de competitividade das empresas. Como resultados, uma baixa articulação das empresas entre si e entre elas e o ambiente institucional.

\subsection{Ambiente Institucional e Recursos de Crédito}

O ambiente institucional é particularmente relevante para o regime de crescimento de um APL no que se refere ao financiamento do crescimento. Perguntados a respeito, 91\%, 90\% e 81\% dos empresários do APLAçaí-GrãoPará, respectivamente nos anos de 2002, 2007 e 2010, informaram ser basicamente com recursos internos que as inovações e a acumulação vêm sendo financiadas (ver Gráfico 10). Embora de significado crescente, o crédito em bancos tem sido uma via pouco importante de financiamento do crescimento das empresas (4\% em 2002 e 2007, 7\% em 2010).

Gráfico 10 - Fontes de financiamento do crescimento das empresas industriais do APLFruta-NePa

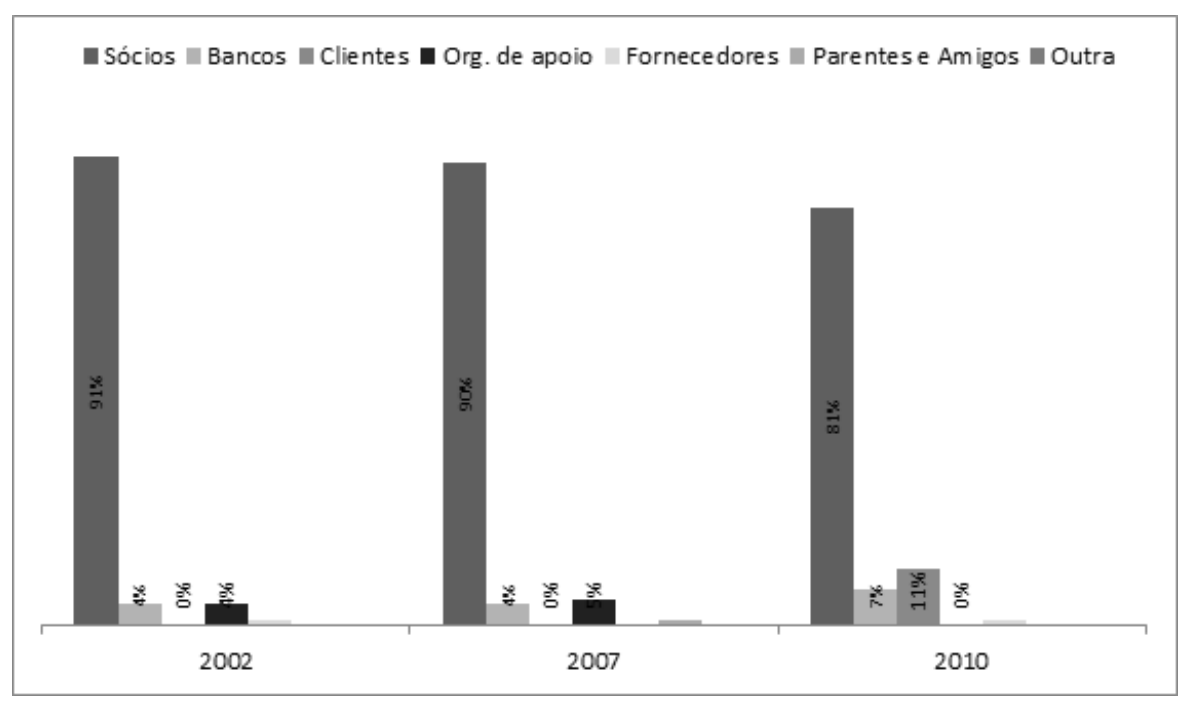

Fonte: Elaboração própria com base em pesquisas de 2003, 2011 e Nacif (2009).

Indagados sobre as razões para esse estado de coisas, os empresários atribuíram, pela ordem de importância, às dificuldades ou entraves burocráticos para se utilizar as fontes de financiamento existentes (61\% em 2002, 88\% em 2010), à exigência e os tipos de garantias (44\% em 2002, 81\%), aos entraves fiscais (17\% em 2002, 66\% em 2007) e à inexistência de linhas de créditos adequadas (11\% em $2002,60 \%$ em 2010). Infere-se, das variações acima, que se avultaram, com o tem- 
po, as dificuldades de acesso a financiamento oficial, na contramão das tendências de crescimento do APLAçaí-GrãoPará.

Um ponto merece ainda atenção: o financiamento por clientes se mostrou, em 2010, a segunda mais importante fonte de financiamento, com 11\%, mais importante que o financiamento por bancos.

\section{Considerações Finais}

Objetivando analisar a constituição, situação e dinâmica do APLAçaí-GrãoPará, produtor de polpa de açaí na região de colonização mais antiga da Amazônia, este artigo compôs resultados de três diferentes pesquisas, desenvolvidas com a metodologia da RedeSist, que cobrem um período de nove anos. A partir do esquema teórico contido na noção de regime de crescimento do APL, avaliamos os fundamentos tecnológicos, as composições de mercado e as mediações institucionais que caracterizam a evolução recente do arranjo.

O regime de crescimento do APLAçaí-GrãoPará não se caracteriza por linearidade, mas sim por instabilidade e provável evolução cíclica. O regime de produtividade, orientado por uma trajetória tecnológica de fundamento endógeno, tem garantido rendimentos crescentes de escala, com a contribuição de uma significativa agenda de inovações tecnológicas incrementais importantes e de ações de cooperação. O grupo de empresas que constitui o núcleo consolidado do APL apresentou desempenho destacado em todos os fundamentos - aumento de tamanho, inovações e cooperações - além de ter desempenho institucional superior às demais. Empresas que se mostraram incapazes de manter o passo com o ritmo médio de crescimento e produtividade ficaram para trás, substituídas por novas, "emergentes" e "recentes", maiores e mais produtivas. O regime de produtividade impôs, portanto, ao APL, associada ao crescimento, uma tendência forte de concentração.

Para o conjunto das empresas, porém, trata-se de dinâmica de crescimento com as condicionalidades associadas a uma taxa média de lucro decrescente, a despeito da produtividade crescente e do preço médio do produto final também em elevação. O regime de demanda conformou-se de modo que pressões de baixa sobre os preços dos produtos finais se combinam com elevação dos preços das matérias primas fundamentais das empresas industriais do APL. As pressões sobre o preço do produto final se exercem mais efetivamente nos compartimentos terminais das cadeias de valor que abastecem o mercado nacional, indicando assimetrias que mereceriam tratamento estratégico e ação política.

O regime institucional, todavia, favorece a crise que pauta as condições vigentes de muitas empresas do arranjo. Esperar-se-ia, mediante as circunstâncias, realce maior do papel da cooperação entre os empresários locais e entre suas 
organizações e o Estado na configuração de estratégias que, em última instância, inscrever-se-iam como políticas de desenvolvimento defensável para a Amazônia, dado que baseado em formas sustentáveis e socialmente inclusivas de uso dos recursos naturais da região. Entretanto, não é o que ocorre. Marcam o arranjo, em realidade, duas fragilidades combinadas na reduzida capacidade de governança: a incapacidade de elaboração e operação de estratégias de resistência às ameaças de ordem competitiva (como uma implicação da) incapacidade de se entender, construir e apresentar como um coletivo.

Por outra parte, há dificuldades no campo das organizações de governo. Primeiro, há déficit de leitura conceitual, teórica e operacional, das organizações de fomento, quanto ao arranjo, sua abrangência, lógica e significado para o desenvolvimento. Segundo, as instituições de crédito de fomento têm mostrado pouca sensibilidade em relação às necessidades e especificidades do arranjo. Sem fontes de financiamento que garantam margem de manobra transacional e base de inovações contínuas, as empresas tendem a se tornar dependentes de fontes de capital associadas a uma hierarquização crescente, com empresas que dependem criticamente de clientes, estabelecendo assimetrias deletérias. Terceiro, revelam-se, pela ausência de políticas, as dificuldades no desenho e implementação de mecanismos de proteção, classificação e criação de barreiras sanitárias com o propósito de conter formas de concorrência predatória, estas reiteradamente presentes nos relatos da pesquisa, baseadas no binômio preço aviltado-baixa qualidade, que, no limite, levam à degradação da confiança dos mercados no APL. Por fim, não há uma política deliberada para o desenvolvimento tecnológico do APL, seja no seu nodo industrial, seja nas trajetórias rurais que o constituem. Sem isso, a gestão do lucro com base no crescimento da produtividade fica comprometida.

Uma pauta de ações de política para a reversão desse quadro se faz urgente. É possível antecipar que uma aceleração, culminando com a confirmação radical da tendência de concentração no nodo industrial do APL, terá repercussões importantes: nos seus fundamentos rurais, que tenderão a enfatizar a plantation, em detrimento de sistemas agroflorestais, e no padrão de distribuição dos resultados do crescimento, que tenderão a concentrar, ao invés de distribuir renda. Tais efeitos se colocariam na contramão de um desenvolvimento que se requer sustentável e inclusivo na Região.

\section{Referências}

AMITRANO, C. R. Instituições e desenvolvimento: críticas e alternativas a abordagem de variedades de capitalismo. 2010. 225 f. Tese (Doutorado em Ciências Econômicas) - Instituto de Economia, Universidade de Campinas, São Paulo, 2010b. 
AMITRANO, C. R. O regime de crescimento econômico brasileiro: uma apreciação sobre o período 1995-2009. In: CARDOSO JÚNIOR, J. C. (Coord.). Brasil em desenvolvimento: Estado, planejamento e políticas públicas. 1. ed. Brasília, DF: 2010a.

APPELBAUM, R. P.; GEREFFI, G. Commodity chains and industrial restructuring in the Pacifc Rim: garment trade and manufacturing. In: GEREFFI, G.; KORZENIEWICZ, M. Commodity chains and global capitalism. West Port: Greenwood Publishing Group, 1994, p. 187-204.

BOYER, R. PETIT, P. Kaldor's growth theories: past, present and prospects for future. In: NELL, E.; SEMMLER, W. (Ed.). Nicholas Kaldor and mainstream economics: confrontation or convergence? London: Macmillan, 1991, p. 485-517.

BRONDIZIO, E. S. The Amazonian caboclo and the açaí palm: forest farmers in the global market. New York: The New York Botanical Garden Press, 2010.

CASSIOLATO, J. E.; LASTRES, H. M. M.; STALLIVIERI, F. (Org.). Arranjos produtivos locais: uma alternativa para o desenvolvimento. Rio de Janeiro: E-Papers, 2008. (Experiências de políticas, v. 2).

CASSIOLATO, J. E.; LASTRES, H. M. O foco em arranjos e sistemas produtivos e inovativos locais. In: LASTRES, H. M.; CASSIOLATO, J. E.; MACIEL, M. L. (Ed.). Pequena empresa: cooperação e desenvolvimento local. Rio de Janeiro: Relume Dumará, 2003, p. 21-34.

CHANDLER, A. D. Strategy and structure. Cambridge: MIT Press, 1962.

COOKE, P.; MORGAN, K. The assocional economy: firms, region and innovation. New York: Oxford University Press, 1998.

COSTA, F A.; ANDRADE, W. D. C.; SILVA, F. C. F. O arranjo produtivo de frutas na região polarizada por Belém do Pará. In: LASTRES, E.; CASSIOLATO, J. (Org.). Estratégias para o desenvolvimento: um enfoque sobre arranjos produtivos locais do norte, nordeste e centrooeste Brasileiros. Rio de Janeiro: E-Papers, 2006, p. 59-78.

COSTA, F A. et al. APL de Frutas no Nordeste paraense e na Região Metropolitana de Belém. Rio de Janeiro: Relatório Técnico, REDESIST, 2011.

COSTA, F. A. et al. Políticas para arranjos produtivos locais no Pará: continuidades e rupturas. In: APOLINÁRIO, V.; SILVA, M. L. (Org.). Políticas para arranjos produtivos locais: análise em estados do Nordeste e Amazônia legal. Natal: EDUFRN, 2010, p. 111-144.

COSTA, F. A. O açaí do Grão-Pará: arranjos produtivos e economia local, constituição e dinâmica (1995-2011). Belém: Núcleo de Altos Estudos Amazônicos, 2016. Originalmente apresentada como tese requisito para promoção ao quadro de professor titular, Universidade Federal do Pará, 2016.

DOSI, G. Institutions and Markets in a Dynamic World. The Manchester School, v. 56, n. 2, p. 119-146, 1988.

. Mudança técnica e transformação industrial: a teoria e uma aplicação à indústria de semicondutores. Campinas: Editora da Unicamp, 2006. 
DOSI, G. The nature of the innovative process. In: DOSI, G. et al. (Ed). Technical change and economic theory. London: Pinter, 1988.

FREEMAN, C. Diffusion: the spread of new technologies to firms, sectors and nations. In: HEERTJE, E. (Ed.). Innovation, technology and finance. Oxford: Blwckwell, 1988.

GERIFFI, G.; KORZENIEWICK, M. (Ed.). Commodity chains and global capitalism. West Port: Greenwood Publishing Group, 1994. $\mathrm{p}$

HOPKINS, T. K.; WALLERSTEIN, I. Commodity chains: Construct and research. In: JOHNSON, B.; LUNDVALL, B. Promovendo sistemas de inovação como resposta à economia do aprendizado crescentemente globalizada. In: LASTRES, H. M. M. CASSIOLATO, J. E.; ARROIO, A. Conhecimento, sistemas de inovação e desenvolvimento. Rio de Janeiro: Editora UFRJ; Contraponto, 2005, p. 83-130.

KOR, Y. Y.; MAHONEY, J. T. Edith Penroses's (1959): contributions to the resoource-based view of strategic management. Journal of Management Studies, v. 41, n. 1, p. 183-191, Jan. 2005 .

LOURENÇO, A. L. C. et al. De volta a Furtado via Kaldor e Thirwall: as teorias heterodoxas de crescimento como suporte para a retomada do enforque furtadiano da questão regional. Revista Econômica do Nordeste, v. 43, n. 2, p. 339-355, abr.-jun. 2012.

LUNDVALL, B. A. National system of innovation: towards a theory of innovation and interactive learning. London: Pinter Publishers, 2002.

MARX, K. O capital. Livro I. São Paulo: Editora Civilização Brasileira, 1978.

MCCOMBIE, J. S. L. Does the aggregate production function imply anything about the laws of production? A note on the Simon and Shaikh critiques. Applied Economics, v. 19, n. 8, p. $1121-1136,1987$.

MYRDAL, G. Economic theory and under-developed regions. London: Duckwoth, 1957.

NACIF, A. M. P. O APL de Polpa de Frutas no Nordeste Paraense e Região Metropolitana de Belém: análise da dinâmica evolutiva, 2003/2007. 145 f. 2009. Dissertação (Mestrado em Planejamento do Desenvolvimento) - Programa de Pós-Graduação em Desenvolvimento Sustentável do Trópico Úmido do Núcleo de Altos Estudos Amazônicos, Universidade Federal do Pará, Belém, 2009.

NALEBUFF, B. J.; BRANDENBURGER, A. M. Co-opetição. Rio de Janeiro: Rocco, 1996.

PENROSE, E. A teoria do crescimento da firma. Campinas-SP: Editora Unicamp, 2006.

PONTE, R. X. Assahy-yukicé, iassaí, oyasaí, quasey, açãy, jussara, manaca, açaí, acay-berry: rizoma. 2013. Tese (Doutorado em Ciências Sociais) - Universidade Federal do Pará, Belém, 2013.

PORTER, M. E. A vantagem competitiva das nações. Rio de Janeiro: Campus, 1989.

ROGEZ, H. Açaí: prepare. Composição e melhoramento da conservação. Belém: EDUFPA, 2000 . 
ROSENBERG, N. Por dentro da caixa-preta: tecnologia e economia. Campinas: Unicamp, 2006.

SETTERFIELD, M. Endogenous growth: a Kaldorian approach. In: HARCOURT, G. C.; KRIESLER, P. (Ed.). Handbook of post Keynesian economics. Oxford: Oxford University Press, 2010.

SILVA, H. Socialização da natureza e alternativa de desenvolvimento na Amazônia Brasileira. 2017. 267 f. Tese (Doutorado em Economia) - Universidade Federal de Minas Gerais, Belo Horizonte, 2017.

THOMPSON, S.: WRIGHT, M. Edith Penrose's contribution to economics and strategy: an overview. Mangerial and Decision Economics, v. 26, n. 2, p. 57-66, 2005.

Recebido em: 21/05/2015. Aceito em: 23/08/2017. 